Vol. 1, Issue. 1 | January - June 2021

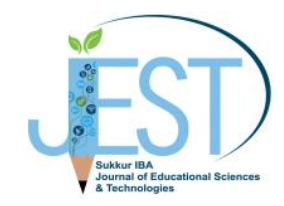

\title{
Effect of Academic Background on Social Competence and its Relationship with Academic Motivation and Academic Performance of First Year University Students
}

\begin{abstract}
Certain differences have been observed in the students belonging to different academic backgrounds hence the purpose of the current research was to explore the effect of academic background (i.e., Cambridge \& HSSC) on Social Competence and to see its relationship with Academic motivation and Academic performance among first year university students. The hypothesis states that there is a significant difference between Social Competence and Academic Motivation of Cambridge and Higher Secondary School Certificate (HSSC) students. There also exists a significant relationship between Social competence, Academic motivation and Academic performance of first year university students. Research design of the study was comparative co-relational survey design. Whereas sampling technique used was purposive convenient sampling. There were $\mathrm{N}=166$ participants (Males $\mathrm{n}=53$ \& Females $\mathrm{n}=113$; Cambridge $\mathrm{n}=90$ \& HSSC $n=76)$ with the age range of $18-23$ years $(M=2.76, S D=1.28)$ from different private and government universities of Karachi. Academic Motivation Scale (Vallerrand, et al., 1992) and Social Competence Scale (Shujja, Malik, \& Khan, 2015) for Adolescence were used for measuring academic motivation and social competence whereas for academic performance previous grades in last given exams were demanded. Statistical analysis including T-test was used for measuring relationship variables of Academic Motivation, Social Competence and Academic Performance among first year university students show no significant relationship. a positive but weak relationship was discovered between social competence and intrinsic motivation. Furthermore, a weak relationship was identified between social competence and gender. This study will help increase insight and improvise the education system and teaching methodologies of both educational systems. Implications for teachers to use innovative methodologies and strategies while teaching to enhance students' social and academic skills to positively influence their performance.
\end{abstract}

Ghania Yamin ${ }^{1}$, Huma Khalid ${ }^{1}$, Fizza Tahir ${ }^{1}$, Erum Khatri ${ }^{1}$ and Sidra Shoaib ${ }^{1}$

${ }^{1}$ Institute of Professional Psychology, Bahria University (Karachi campus)

Corresponding author's email: sidrashoaib175@yahoo.com

Keywords: Academic background, Social comptence, Academic motivation, Academic performance, University students, Education systems in Pakistan, Intermediate system, Cambridge system, Learning, Corelational study.

\section{Introduction}

Pakistan is a developing country, currently facing issues and challenges in the education sector. Good education in the initial stages i.e., primary and secondary education can therefore provide a sound foundation to further go for higher education in universities. This early education can help develop student's social competence by enhancing self-confidence, self-efficacy, leadership skills etc. This will further influence their attitude in the phase of attaining higher education in universities. All the universities whether private or government, provide almost same level of education and same level of challenge to students which keeps them motivated towards studies. University is the place where students enter a new phase of life where they make new friends and try to create a relationship with them as to make the best of their time at the university (Mahamod \& Somasundram, 2017; Memon, 2007).

The education system in Pakistan has three levels. The first five years of education are called Primary years whereas the following three years are middle years. Further two years are referred to as secondary education which concludes high school as student clears board examination known as Secondary School Certificate Examination (SSCE) more commonly "Matric" exam. The students now enroll into a two-year education program known Higher Secondary School Certificate (HSSC) which is more commonly known as 
Intermediate. After passing HSSC exam, the student enters in a 4-year bachelor's program offered by Higher Education Commission (HEC). A separate education system called Cambridge system which is General Certificate of Education (GSE), where SSCE is replaced by ordinary level, O' level and HSC is replaced by advanced level, A' level (Scholaro, 2018).

HSSC system is merely focused on learning through reading and writing. Writing is one of the tools through which a person can learn. As writing estimates human speech and enhances learning strategies. Writing to learn can create a small but positive impact on academic achievement of students (Bangert-Drowns, Hurley, \& Wilkinson., 2004). The HSSC system focuses more on memorization and rote learning. Whereas, the Cambridge system focuses more on a subject's understanding and rethinking about a learned phenomenon. The subjects and grading criteria are also different in both education systems (Shaikh, 2018). Academic backgrounds: HSSC and Cambridge, both have their own methodologies and strategies they use to educate students. Based on these differences, the current study aims to find out these differences as these students come together for the first time at university level and these differences are identified here. These along with the strengths of both education systems polishes student's various skills such as leadership, self-confidence, adaptability, sociability, self-efficacy and social initiative which contributes to their social competence.

\subsection{Social competence}

It is defined as the possession and use of ability to integrate thinking, feeling and behavior to achieve social tasks and outcomes valued in the host setting and culture. They argue that social competence has component variables that vary along continuous dimensions and is socially constructed through social interactions in different contexts. Social competence is therefore not only knowledge and information processing capability, but also a set of component skills or procedures applied conditionally (Topping, Bremner, \& Holmes, 2000). These set of skills or procedures are acquired overtime with previous experiences such as self-efficacy beliefs are developed as a result of performing similar tasks.

Self-efficacy: It is defined as the belief we have in our own abilities, specifically our ability to meet the challenges ahead of us and complete a task successfully (Akhtar, Ghayas, \& Adil, 2013). Self-efficacy helps to influence academic achievement on basis of self-regulated learning (Zimmerman, Bandura, \& Martinez-Pons, 1992). Several studies have shown positive relation between self-efficacy, persistence and social integration (Torres, 2001).

Sociability: It is described as the tendency to affiliate and to prefer being with others i.e. A-motivation (Cheek \& Buss, 1981). Social responsibilities facilitate learning and performance outcomes from a motivational perspective by providing incentives in the form of positive interactions with teachers and peers (Wentzel, 1991).

Adaptability: Adaptability is defined as appropriate cognitive, behavioral, and/or affective adjustment in the face of uncertainty and novelty (Martin, Nejad, Colmar, \& Liem, 2013). Academic world changes constantly therefore, students that are adaptive to these changes and adjust to constraints and opportunities in social environment show adaptive patterns in the form of academic motivation (Heckhausen \& Wrosch, 2015). The degree of social interaction of students with peers' tempers with their emotional regulation influences their social adaption (Rubin, Coplan, Fox, \& Calkins, 1995).

Self-confidence: It is a significant predictor of students' academic performance as it increases level of motivation and expectation of academics (Tavani \& Losh, 2003). Student's self-confidence is a necessary trait for attaining higher academic achievement/performance (Lazar, Jihyun, Wenshu, \& David J., 2012) also true for a good oral performance achievement (Al-Habaish, 2012). This can result in social competence skills and a motivation for academic. This shows role of self-confidence is essential for both academic and verbal performances using communication and interpersonal problem-solving skills (Erozkan, 2013).

Social initiative: It is an initiative that is sustainable and has the potential for a positive impact on society (Hess \& Warren, 2008). Exploring social initiative as a form of social competence in adolescents was studied as a function of history of interpersonal relationships, showed social relationship experiences in younger adolescents and parental relationships in older adolescents as the predictors (Barber \& Erickson, 2001). Adolescents have social interactions in their academic settings and these experiences stem academic motivation or amotivation influencing their achievements (Mahamod \& Somasundram, 2017). 
Leadership: Effective leadership requires developed social skills (Riggio \& Reichard, 2008). Good schools employ approaches to develop their students as the leaders of future such as participating in leadership education and training programs leads to educational and personal development such as leadership skills, personal and societal views (Cress, Astin, Zimmerman-Oster, \& Burkhardt, 2001).

\subsection{Academic Motivation}

It is a student's desire (as reflected in approach, persistence, and level of interest) regarding academic subjects when the student's competence is judged against a standard of performance or excellence (DiPerna \& Elliott, 1999). According to Gresham (1988), Academic motivation is a subtype of the general construct of reflectance motivation, which is defined as the need to be successful or effective in dealing with one's environment. A student deals with various educational outcomes including learning, performance, engagement and persistence (Utvær \& Haugan, 2016). Students deal with these situations using social skills as they are important in many aspects of an individual's life including social and academic success (Elliott, Malecki, \& Demaray, 2001).

\subsection{Academic performance}

Academic performance or Academic achievement in school years can be defined as, "Achieving cognitive goals that are set for multiple subjects for the acquisition of knowledge within the academic period" (Steinmayr, MeiBner, Weidinger, \& Wirthwein, 2014). Social environment also influences academic performance as carefully identifying social situations and being aware of one's and others' emotions and making decisions on basis of the social context will enable forming positive relationships with others (Zins, Weissbert, Wang, \& Walberg, 2004). According to a study exploring components of social competence that influence learning motivation and academic achievement indicated intrinsic motivation to have a considerable effect on all three variables (Zsolnai, 2002).

\subsection{Theoretical Framework}

The concept of Academic background is based on two of the major education systems of Pakistan i.e., Higher Secondary School Certificate (HSSC) and Cambridge system. The difference in teaching methodology, grading criteria and learning environment of both systems, may affect students differently in their social and performance skills (Shaikh, 2018). A study was conducted on Academic Background of students and it was revealed that students' academic background and attitude significantly correlated with their academic performance in one of the freshman courses (House, 1998). Considering, self-determination theory by Deci and Ryan (2000) which focuses on self-determined or autonomous and controlled behaviors i.e., intrinsic and extrinsic motivation. It suggests that positive change in academic competence may result in enhancing academic self-determination which positively impacts academic motivation and academic performance of the students (Michielle, Robert, \& Frederic, 1995). Hence, the theoretical framework will focus on students as they enter their higher education phase of professional life in first years of university from their respective academic backgrounds: HSSC or Cambridge with learned social and motivational skills. It will study a relationship between two predicting variables i.e. Social Competence and Academic Motivation which have an impact on the criterion variable i.e. Academic Performance. Social Competence also includes six subconstructs for measurement which are 1) Self-efficacy, 2) Sociability, 3) Adaptability, 4) Self-confidence, 5) Social initiative and 6) Leadership. Academic Motivation is also measured in terms of its three subconstructs 1) Intrinsic Motivation 2) Extrinsic Motivation and 3) A-motivation. Whereas, Academic performance will be measured through previous and current grades in first year of university.

\section{Review of Literature}

The impact of two contrasting examination patterns i.e., Higher Secondary School Certificate (HSSC) and O' levels was studied on teaching style at secondary and higher secondary level in Pakistan. In contrast, both systems focus on demonstrative and lecture methods to teach. HSSC teachers prefer reading and recitation methods, whereas Cambridge teachers are more inclined towards asking questions and answers to evaluate students on the subject and also encourage class participation and interaction. The results showed that teachers varied their teaching style to get good results or higher academic performance of students (Mahmood \& Shinohara, 2002; Adnan \& Mahmood, 2014; Ghulam \& Anwar, 2011).

From the above literature, it can be concluded that differences among both education systems have created a general opinion in public that Cambridge system is much advanced and tough in comparison with HSSC. As reported in various studies, there exists an acrobatic link between education and development of students set of skills such as HSSC education system focuses more on rote learning and memorization whereas, Cambridge focuses more on a topic's understanding and rethinking about the learnt phenomenon. We can 
also see established positive links between academic and social motivational constructs on student's motivation and academic performance in various studies (Wigfield, 1998). Therefore, this research will figure out authenticity of this general public opinion by studying academic and social motivational constructs such as social competence and academic motivations' effects on academic performance in the light of both education systems: HSSC and Cambridge.

This study may help to eliminate previously held perceptual schema about both the education systems as university helps to merge students and brings them at the same level. This study encourages students to involve, participate and compete with one another through assignments or presentations etc. to foster academic motivation. Comparing both systems, the strengths and weakness of each can be used to tackle performance and bring further improvement in various areas of students other than just academics such as help empower and mold students' cognitions, skills and abilities in more practical and logical ways. Both educational systems follow different teaching methodologies, curriculum, evaluation methods etc. Therefore, there exists a greater need to study the difference it exhibits in terms of implications in vocational guidance, job, career development etc.

\section{Methodology}

\subsection{Research hypothesis}

- There will be a significant difference in Social Competence of Cambridge and Higher Secondary School Certificate (HSSC) students.

- There will be a positive relationship between Social Competence, Academic Motivation and Academic Performance of first year university students.

\subsection{Research design}

The current study is a quantitative research approach to a comparative co-relational survey design research to study relationship of social competence and its relationship with their academic motivation and academic performance in first years of their university to analyze the differences of academic background of Higher Secondary School Certificate (HSSC) and Cambridge students.

\subsection{Sample}

First year university students aged between $18-23$ years $(\mathrm{N}=166, \mathrm{M}=2.76, \mathrm{SD}=1.28)$ from Higher Secondary School Certificate (HSSC) and Cambridge academic background were approached through convenient purposive sampling, which is a non-probability sampling technique.

\subsection{Inclusion criteria of research participants}

- Participants admitted in private or government universities in Karachi, Pakistan.

- Participant between the age range of 18-23 years were selected for the study.

- Participants from the education backgrounds of HSSC or Cambridge were selected for the study.

\subsection{Measures}

3.5.1. Informed Consent Form

Participants were asked to fill out the informed consent form before administering the scales. Participants were informed briefly regarding the purpose of the study and their right to withdraw at any time. They were ensured about the confidentiality of their personal information.

\subsubsection{Demographic Information Form}

The demographic information form was used to collect basic information about the participants. The demographic information form inquired about the participants; Gender, Educational background, University, Department, Current Semester, Previous and Current Grades.

3.5.3. Social Competence scale for Adolescents (SCSA) (Shujja, Malik, \& Khan, 2015)

It is a self-report measure of social competence in adolescents. It was created by Sultan Shujja, Farah Malik and Nishi Khan (2015). It consists of 53 items divided into includes six sub-scales i.e., self-efficacy, sociability, adaptability, leadership, self-confidence and social initiative. The score for each item ranges from one to four (1-4) on a Likert scale ranging from 'Never' to 'Always'. Score 1 was assigned to 'Never' and 4 to 'Always'. There are 5 items that are reverse scored. The internal alpha co-efficient range is .60-.87 indicating it to be a reliable instrument to measure social competence of adolescents. 
3.5.4. Academic motivation Scale (AMS)(Vallerrand, et al., 1992)

It is a self-report questionnaire by Vallerrand, R. J., Pelletier, L. G., Blais, M. R., Briere, N. M., Senecal, C. \& Vallieres, E. (1992). It consists of 28 items divided into seven subscales to assess three dimensions of motivation i.e., intrinsic, extrinsic and Amotivation. The items are scored on a 7-point Likert scale ranging from 1 indicating 'Does not correspond at all' to 7 indicating 'Corresponds exactly'. The translated English version of scale has mean alpha value .81 indicating satisfactory level of internal consistency.

\subsection{Procedure}

Permission was sought from the different universities. Questionnaires were administered after taking informed consent and briefing regarding confidentiality and purpose of study. Participants were encouraged to ask questions in case of any query. After they agreed to participate in the study, they were asked to fill the forms in the sequence of Informed consent, demographic form Social Competence scale for Adolescents (SCSA) (Shujja, Malik, \& Khan, 2015), Academic Motivation Scale (AMS) (Vallerrand, et al., 1992) and Academic Performance was evaluated using their previous/current grades. Convenient purposive sampling was used to collect data from males and females of different private and government universities in Karachi. These participants can be considered as representatives of Higher Secondary School Certificate (HSSC) and Cambridge academic background as those not fitting the inclusion criteria were not included. The results were analyzed using Statistical Package of Social Sciences (SPSS-22) to test statistical significance of the variables after manually scoring the questionnaires.

\section{Results}

In results, the demographic variable of participants is discussed along with descriptive statistics of main variables. The results of the current study were obtained through SPSS 22 Version. Descriptive Analysis and Paired Sample T-Test were performed to obtain the results.

TABLE I. Frequency and percentages of demographic variables $(\mathrm{N}=166)$.

\begin{tabular}{lll}
\hline Variables & $\boldsymbol{f}$ & $\boldsymbol{\%}$ \\
\hline Educational Background & 76 & 45.8 \\
Intermediate & 90 & 54.2 \\
Cambridge & & \\
\hline Gender & 53 & 31.9 \\
$\quad$ Male & 113 & 68.1 \\
$\quad$ Female & & \\
\hline University & 94 & 56.6 \\
Private & 72 & 43.4 \\
$\quad$ Government & & \\
\hline Department & 57 & 34.3 \\
$\quad$ Arts & 25 & 15.1 \\
Science & 70 & 42.2 \\
$\quad$ Social science & 14 & .84 \\
$\quad$ Business & & \\
\hline Current Semester & 91 & 54.8 \\
$\mathbf{1}^{\text {st }}$ semester & 75 & 45.2 \\
$\mathbf{2}^{\text {nd }}$ semester & & \\
\hline
\end{tabular}


Previous Grades (Intermediate/A-levels)
A
61
36.7
B
67
40.4
C
27
16.3
D
11
6.6

\section{Current Grades}

A

B

C

D

E
89

53.6

Note: $\mathrm{f}=$ frequency.

The above-mentioned Table 1 shows the frequency distribution and the percentages of all the demographic variables that were considered in the present study and the focus of the study was to target the true representative sample of the population in the current study.

Table 2. Table statistics and alpha reliability co-efficient, univariate normality of study variables $(\mathrm{N}=166)$

TABLE II. Range

\begin{tabular}{llcccccccc}
\hline Variables & Items & $\mathbf{N}$ & $\boldsymbol{\alpha}$ & $\mathbf{M}$ & $\mathbf{S D}$ & $\mathbf{S K}$ & $\mathbf{K}$ & Actual & Potential \\
\hline SC & 53 & 165 & .87 & 108.01 & 16.56 & -.17 & -.21 & $118-203$ & $53-212$ \\
\hline SE & 14 & 165 & .71 & 47.10 & 4.89 & -.64 & .09 & $31-56$ & $14-42$ \\
\hline ADB & 8 & 166 & .59 & 23.81 & 3.63 & -.09 & -.50 & $15-32$ & $8-32$ \\
\hline LD & 4 & 166 & .45 & 12.69 & 1.93 & -.53 & -.01 & $7-16$ & $4-16$ \\
\hline SCD & 8 & 166 & .41 & 22.28 & 3.40 & .14 & -.62 & $15-32$ & $8-32$ \\
\hline SI & 4 & 166 & .79 & 10.65 & 3.09 & -.27 & .82 & $4-16$ & $4-16$ \\
\hline SCB & 15 & 166 & .71 & 44.79 & 5.98 & -.06 & -.45 & $31-58$ & $15-60$ \\
\hline ACM & - & - & - & - & - & - & - & - & - \\
\hline AM & 4 & 165 & .82 & 10.12 & 6.01 & .86 & .05 & $4-28$ & $4-28$ \\
\hline EM & 12 & 166 & .87 & 61.13 & 14.12 & -.56 & -.35 & $19-84$ & $12-84$ \\
\hline IM & 12 & 166 & .84 & 58.59 & 12.38 & -.30 & -.38 & $22-83$ & $12-84$
\end{tabular}

Note $:$ SC $=$ Social competence, $\mathrm{SE}=$ Self efficacy, $\mathrm{ADB}=$ Adaptability, $\mathrm{LD}=$ leadership, $\mathrm{SCD}=$ Selfconfidence, $\mathrm{SI}=$ Social initiative, $\mathrm{SCB}=$ Sociability, $\mathrm{AM}=$ Amotivation, $\mathrm{EM}=$ Extrinsic motivation, $\mathrm{IM}=$ Intrinsic motivation, $\mathrm{ACM}=$ Academic motivation, $\mathrm{SK}=$ Skewness, $\mathrm{K}=$ kurtosis.

The above table shows the values Mean, Standard deviation, Skewness and Kurtosis, which shows that the data of the current study is normally distributed. It also shows alpha reliabilities of the Social Competence and Academic Motivation variables along with their sub-variables. 
Table 3. T - Table showing the relationship based on Academic background between Social competence, Self-efficacy, Adaptability, Leadership, Self-confidence, Social initiative, sociability, Amotivation, Intrinsic motivation and extrinsic motivation, Current grades and Previous grade $(\mathrm{N}=166)$.

TABLE III. Relationship

\begin{tabular}{|c|c|c|c|c|c|c|c|c|c|}
\hline \multirow[b]{3}{*}{ Variables } & \multirow[b]{3}{*}{$\mathbf{N}$} & \multirow[b]{3}{*}{$\mathbf{M}$} & \multirow[b]{3}{*}{ SD } & \multirow[b]{3}{*}{ Std. } & \multirow{3}{*}{$\mathbf{t}$} & \multirow{3}{*}{$\mathbf{P}$} & \multicolumn{2}{|c|}{$95 \% \mathrm{CI}$} & \multirow{3}{*}{$\begin{array}{c}\text { Cohen's } \\
\text { d }\end{array}$} \\
\hline & & & & & & & $\mathbf{L L}$ & $\mathbf{U L}$ & \\
\hline & & & & & & & & & \\
\hline \multicolumn{10}{|l|}{ SC } \\
\hline Intermediate & 75 & 159.3 & 15.9 & & $\overline{-}$ & 0.18 & \multicolumn{2}{|c|}{$\begin{array}{r}-8.54 \\
1.66\end{array}$} & \\
\hline Cambridge & 90 & 162.7 & 16.9 & & & & & & \\
\hline \multicolumn{10}{|l|}{ SE } \\
\hline Intermediate & 75 & 46.45 & 4.89 & .56 & $\begin{array}{c}- \\
1.56\end{array}$ & .12 & -2.69 & .31 & \\
\hline Cambridge & 90 & 47.64 & 4.86 & .51 & & & & & \\
\hline \multicolumn{10}{|l|}{ ADB } \\
\hline Intermediate & 76 & 23.06 & 3.52 & .40 & $\begin{array}{c}- \\
2.49\end{array}$ & .01 & -2.48 & -.29 & .38 \\
\hline Cambridge & 90 & 24.45 & 3.61 & .38 & & & & & \\
\hline \multicolumn{10}{|l|}{ LD } \\
\hline Intermediate & 76 & 12.44 & 1.87 & .21 & $\begin{array}{c}- \\
1.50\end{array}$ & .13 & -1.04 & .14 & \\
\hline Cambridge & 90 & 12.90 & 1.97 & .20 & & & & & \\
\hline \multicolumn{10}{|l|}{ SCD } \\
\hline Intermediate & 76 & 22.32 & 2.94 & .33 & .11 & .91 & -.98 & 1.10 & \\
\hline Cambridge & 90 & 22.25 & 3.76 & .39 & & & & & \\
\hline \multicolumn{10}{|l|}{ SI } \\
\hline \multirow[t]{2}{*}{$\begin{array}{l}\text { Intermediate } \\
\text { Cambridge }\end{array}$} & 76 & 10.34 & 3.13 & .35 & 1.20 & .23 & -1.53 & .37 & \\
\hline & 90 & 10.92 & 3.06 & .32 & & & & & \\
\hline
\end{tabular}




\section{SCB}

$\begin{array}{ccccccccc}\begin{array}{c}\text { Intermediate } \\ \text { Cambridge }\end{array} & 76 & 45.01 & 5.93 & .68 & .43 & .66 & & 2.24 \\ & 90 & 44.61 & 6.05 & .63 & & & & \end{array}$

\begin{tabular}{|c|c|c|c|c|c|c|c|c|c|}
\hline $\mathbf{A M}$ & & & & & & & & & \\
\hline Intermediate & 75 & 10.50 & 5.71 & .65 & .73 & 46 & -1.16 & 2.55 & \\
\hline Cambridge & 90 & 9.81 & 6.27 & .66 & & & & & \\
\hline \multicolumn{10}{|l|}{ EM } \\
\hline Intermediate & 76 & 60.77 & 13.3 & 1.53 & -.29 & .76 & -5.01 & 3.69 & \\
\hline Cambridge & 90 & 61.43 & 14.81 & 1.56 & & & & & \\
\hline \multicolumn{10}{|l|}{ IM } \\
\hline Intermediate & 76 & 59.10 & 12.50 & .07 & .49 & .62 & -2.86 & 4.76 & \\
\hline Cambridge & 90 & 58.15 & 12.33 & .10 & & & & & \\
\hline \multicolumn{10}{|l|}{ PG } \\
\hline Intermediate & 76 & 1.57 & .66 & .07 & -5.1 & .00 & -.92 & -.41 & .81 \\
\hline Cambridge & 90 & 2.23 & .94 & .10 & & & & & \\
\hline \multicolumn{10}{|l|}{ CG } \\
\hline Intermediate & 76 & 1.61 & .69 & .08 & -.14 & .88 & -2.5 & .22 & \\
\hline Cambridge & 90 & 1.64 & .08 & .08 & & & & & \\
\hline
\end{tabular}

Note: $\mathrm{SC}=$ Social competence total, $\mathrm{SE}=$ Self efficacy, ADB = Adaptability, LD = leadership, SCD = Selfconfidence, $\mathrm{SI}=$ Social initiative, $\mathrm{SCB}=$ Sociability, $\mathrm{AM}=$ Amotivation, $\mathrm{EM}=$ Extrinsic motivation, $\mathrm{IM}=$ Intrinsic motivation

The above-mentioned table 3 shows that there is no significant difference in the Social competence and Educational background (Higher Secondary Education HSSC and Cambridge education system CES) of the first-year university students.

It also indicates that there is no significant relationship between Social competence (self- efficacy, leadership, self-confidence, social initiative and sociability) except for Adaptability. Adaptability in students from Cambridge background is greater than HSSC with the cohen's d value of .38. There is no significant difference observed in the Academic motivation (Amotivation, Intrinsic motivation and extrinsic motivation). Previous grades of Cambridge system are greater than HSSC with the cohen's d of .81 . 
Table 4. Correlations between Social competence (Self-efficacy, Sociability, Adaptability, Self- confidence, social initiative \& leadership), academic motivation (intrinsic, extrinsic and a motivation) and academic performance (Previous grades, current grades $(\mathrm{N}=166)$.

TABLE IV. Correlation

\begin{tabular}{|c|c|c|c|c|c|c|c|c|c|c|c|c|c|}
\hline \multicolumn{2}{|c|}{ Variables } & 1 & 2 & 3 & 4 & 5 & 6 & 7 & 8 & 9 & 10 & 11 & 12 \\
\hline 1 & $\mathrm{SC}$ & - & $\begin{array}{c}.82 * \\
*\end{array}$ & $\begin{array}{c}.76^{*} \\
*\end{array}$ & $\begin{array}{c}.62 * \\
*\end{array}$ & $\begin{array}{c}49 * \\
*\end{array}$ & $\begin{array}{c}.67 * \\
*\end{array}$ & $\begin{array}{c}.79 * \\
*\end{array}$ & $\begin{array}{c}- \\
.10\end{array}$ & $\begin{array}{c}.25^{*} \\
*\end{array}$ & $\begin{array}{c}.34^{*} \\
*\end{array}$ & $\begin{array}{l}.0 \\
0\end{array}$ & -.12 \\
\hline 2 & SE & & - & $\begin{array}{c}.61 * \\
*\end{array}$ & $\begin{array}{c}.48 * \\
*\end{array}$ & $\begin{array}{c}.35^{*} \\
*\end{array}$ & $\begin{array}{c}.37 * \\
*\end{array}$ & $\begin{array}{c}.55^{*} \\
*\end{array}$ & $\begin{array}{c}19 \\
*\end{array}$ & $\begin{array}{c}.26^{*} \\
*\end{array}$ & $\begin{array}{c}.30 * \\
*\end{array}$ & $\begin{array}{l}- \\
.0 \\
0\end{array}$ & $\begin{array}{c} \\
.16 \\
*\end{array}$ \\
\hline 3 & ADB & & & - & $\begin{array}{c}39 * \\
*\end{array}$ & $\begin{array}{c}.35 * \\
*\end{array}$ & $\begin{array}{c}.44 * \\
*\end{array}$ & $\begin{array}{c}.47 * \\
*\end{array}$ & $\begin{array}{c}- \\
.05\end{array}$ & $.17 *$ & $\begin{array}{c}.26 * \\
*\end{array}$ & .10 & -.04 \\
\hline 4 & LD & & & & - & $\begin{array}{c}30 * \\
*\end{array}$ & $\begin{array}{c}.41 * \\
*\end{array}$ & $\begin{array}{c}.39 * \\
*\end{array}$ & $\begin{array}{c}- \\
.03\end{array}$ & .13 & $\begin{array}{c}- \\
.26^{*} \\
*\end{array}$ & $\begin{array}{l}- \\
.0 \\
0\end{array}$ & -.13 \\
\hline 5 & SCD & & & & & - & $.17 *$ & .12 & $\begin{array}{c}.23^{*} \\
*\end{array}$ & .05 & $.21^{*}$ & -.07 & -.10 \\
\hline 6 & SI & & & & & & - & $\begin{array}{c}.25^{*} \\
*\end{array}$ & .08 & .12 & $.19 *$ & .01 & -.03 \\
\hline 7 & SCB & & & & & & & - & $\begin{array}{c}- \\
.02\end{array}$ & $\begin{array}{c}.24 * \\
*\end{array}$ & $\begin{array}{c}.25^{*} \\
*\end{array}$ & -.04 & -.07 \\
\hline 8 & $\mathrm{AM}$ & & & & & & & & - & $\begin{array}{c}- \\
.15 *\end{array}$ & $\begin{array}{c}- \\
22 * \\
*\end{array}$ & -.03 & .02 \\
\hline 9 & EM & & & & & & & & & - & $\begin{array}{c}.62 * \\
*\end{array}$ & 0.3 & 0.4 \\
\hline $\begin{array}{l}1 \\
\mathbf{0}\end{array}$ & IM & & & & & & & & & & - & .03 & -.05 \\
\hline $\begin{array}{l}1 \\
1\end{array}$ & PG & & & & & & & & & & & - & $.31 *$ \\
\hline $\begin{array}{l}1 \\
2\end{array}$ & $\mathrm{CG}$ & & & & & & & & & & & & - \\
\hline
\end{tabular}

Note: $\mathrm{SC}=$ Social competence, $\mathrm{SE}=$ Self efficacy, ADB = Adaptability, LD = leadership, $\mathrm{SCD}=$ Selfconfidence, $\mathrm{SI}=$ Social initiative, $\mathrm{SCB}=$ Sociability, $\mathrm{AM}=$ Amotivation, $\mathrm{EM}=$ Extrinsic motivation, $\mathrm{IM}=$ Intrinsic motivation, $\mathrm{PG}=$ Previous grades, $\mathrm{CG}=$ Current grades. ${ }^{*} * \mathrm{P}<0.01$

The social competence total (SCT) also shows strong positive relationship with its sub-variables; selfefficacy, adaptability, sociability whereas it has a moderate positive relationship with leadership. Amotivation has a significant negative but weak relationship (-.10) with Social competence. There is a positive but weak relationship between social competence and intrinsic motivation (.34**) and a weak positive relationship with Extrinsic motivation. There is a negative but weak relationship between Social competence and Current performance. There is no significant relationship between Academic performance and Academic motivation (amotivation, intrinsic motivation and extrinsic motivation). There exists a significant positive but weak significant relationship between Current and previous academic performance. 
Table 5. Regression analysis showing Social competence as a determinant of intrinsic motivation in First year university students.

TABLE V. Regression Analysis

\begin{tabular}{|c|c|c|c|c|c|}
\hline \multicolumn{6}{|c|}{ Intrinsic Motivation } \\
\hline & B & B & $\mathrm{P}$ & $\mathrm{R}^{2}$ & $\Delta R^{2}$ \\
\hline & .25 & .32 & 4.41 & .11 & .11 \\
\hline
\end{tabular}

Note. $\mathrm{B}=$ standardized beta, $\mathrm{R} 2=\mathrm{R}$-squared, $\&, \Delta R 2=$ Adjusted $\mathrm{R}$ - Squared

The Table 5 shows a change in predictor variable of Social Competence will result in a significant $11 \%$ change in the criterion variable of intrinsic motivation.

\section{Discussion}

The hypothesis intended to study relationship of social competence, academic motivation and academic performance of first year university students from HSSC and Cambridge background. Results showed that there exists no significant difference in social competence of Intermediate and Cambridge students. The calculated social competence of intermediate students was $97 \%$ and social competence of Cambridge students was $95.5 \%$. Majority of the students already had high social competence so no differences could be interpreted. The data was collected from students after they had given some of their examination as well as completed projects with their peers, which could have affected their reporting on the questionnaires. Due to the limited literature on education systems in Pakistan and its effect on social competence, the current research would be efficient for future researchers working in this domain.

A study by Legault (2006), showed social support to be negatively related with academic Amotivation therefore concluding that enough social support is important for intrinsic as well as self-determined extrinsic academic motivation. Similarly, in this study Amotivation (absence of motivation) has a negative but weak relationship with Social Competence. However, a positive but weak relationship was found between Social Competence and intrinsic motivation as well as extrinsic motivation of the students i.e., group learning would encourage students to socialize and study among themselves or higher education encourages group learning such as group projects or presentations etc. This was also supported in the literature, as most of the degree programs at university offer courses to the students in which the student must present the given project or presentation within a group in front of the class, this practice encourages students to socialize, study in group and boost up their self-confidence. This articulate interest in their studies which leads motivation towards academics. A series of studies were done to analyze the role of social support and academic amotivation, the results of the study were revealed that social support was negatively related with academic amotivation (Legault, Green-Demers, \& Pelletier, 2006).

In this study, the academic performance showed a weak positive relationship between the previous and current academic performance of students. Another significant finding revealed that there exists no relationship between Academic Motivation and Academic Performance. Therefore, indicating various factors to predict academic performance among which, previous performance might act as one of the predictors. As found out in the research, previous Academic Performance was found to be the most significant predictor of University Performance. Other factors such as integration into university, selfefficacy and employment responsibility also predict Academic Performance in university(Schweitzer \& Mc Kenzie, 2010).

Masroor (2018), study indicated Cambridge system mostly focus on practical and logical thinking whereas HSSC focuses on rote learning. This interpretation can also be linked to the literature as discussed by Shaikh (2018), in his study that there is a difference in grading criteria, teaching methodologies and learning environment of both education systems. The result analysis of this study showed that Cambridge students scored significantly higher on previous grades and adaptability in comparison to HSSC students.

Further investigation unveils that there is no significant difference between social competence, academic motivation and academic performance based on academic background of first year university students. However, similar teaching practices in university for all students i.e., the materials/ways through which knowledge is conveyed are similar. This might lead to equal academic motivation and performance in first year university students despite different backgrounds. Similarly, the social competence and academic 
motivation was revealed to be unrelated. Whenever a student enters the university, the community considers the students as he/she has achieved a milestone by getting admission in university. Students get motivated by the way they are treated after getting enrolled in their higher studies. This treatment can produce motivation towards studies rather than their social competence. Also, there is no positive relationship between social competence and academic performance. It can largely be attributed to the impact of our culture and surrounding. When the student enters university, he/she feel accomplished, their self-esteem boosts up leading them to believe that they don't need to put much efforts towards their studies. This might act as a contributing factor to above discussed point. The table further states that there is no positive relationship between academic motivation and academic performance of first year university students. In Pakistani culture, students who enter in university, their motivation is high since their parents consider that if their child can enter in the university, he/she must continue and graduate with a decent performance and grades. Pressure of showing results leads to intensify the performance in students. Similarly, in our society a child with only an intermediate or an O level qualification has no such acceptance and the opportunities for work are limited as well. These pressures can be contributing factors towards Academic Performance rather than Academic motivation of students. Due to limitation of literature on this point this study can be efficient.

Interpretation of result shows social competence and intrinsic motivation showing a positive but weak relationship between the two variables. The regression analysis shows that a change in the predictive variable of social competence will result in significant change (11\%) in the criterion variable of intrinsic motivation. Benware \& Deci (1984), study discloses that students who are taught in way to teach others with their capability are more intrinsically motivated than those who are taught just to be examined. In Asian culture, it can be said that the motivation of a student towards their academic is usually because of the social pressure from family to graduate and to gain acceptance from society in order to walk proudly with them.

Results of the study conducted show significant differences from the available literature. Reinforcing the role of cultural differences in displaying the result. Indicating these variables can be further explored in our Asian culture to get further insight and awareness in regards to other variables as well.

\section{Conclusion}

It can be concluded that there exists no significant difference in Social Competence between the twoeducation system i.e., HSSC and Cambridge. Social Competence skills and academic performance does not differ according to their Academic Background. However, there was a positive but weak relationship found between Social Competence and Academic Motivation (Intrinsic and Extrinsic).

\section{Recommendations}

This study was conducted on university students. In the future, researchers can focus on school or college age students to see early years of learning and development. This can be done taking into account other education systems as well with a larger sample. This can be further studied by conducting a qualitative study.

\section{REFERENCES}

Adnan, U., \& Mahmood, A. M. (2014). Impact of Public Examination on Teaching of English: A Washback Perspective. Journal of Education and Practice, 5(2). Retrieved from http://www.iiste.org/

Akhtar, S., Ghayas, S., \& Adil, A. (2013). Self-efficacy and optimism as predictors of organizational commitment among bank employees. International Journal of Research Studies in Psychology, 2(2), 33-42. doi:10.5861/ijrsp.2012.131

Al-Habaish, S. M. (2012). The Correlation between General Self- Confidence and Academic Achievement in the Oral Presentation Course. Theory and Practice in Language Studies, 2(1), 60-65. Retrieved from http://repository.taibahu.edu.sa

Bangert-Drowns, R. L., Hurley, M. M., \& Wilkinson. (2004). The Effects of School-Based Writing to Learn Interventions on Academic Achievement: A Meta-Analysis. SAGE Journals, 74(1), 29-58. doi: $10.3102 \% 2 \mathrm{~F} 00346543074001029$

Barber, B. K., \& Erickson, L. D. (2001). Adolescent Social Initiative: Antecedents in the Ecology of Social Connections. Journal of Adolescent Research, 16(4), 326-354. doi:10.1177/0743558401164003

Benware, C. A., \& Deci, E. L. (1984). Quality of Learning with an Active versus Passive Motivational Set. American Educational Research Journal, 21(4), 755-765. doi:10.3102/00028312021004755

Cheek, M. J., \& Buss, H. A. (1981). Shyness and sociability. Journal of Personality and Social Psychology, 41(2), 330-339. doi:10.1037/0022-3514.41.2.330 
Cress, C. M., Astin, H. S., Zimmerman-Oster, K., \& Burkhardt, J. C. (2001). Developmental outcomes of college students' involvement in leadership activities. Journal of College Student Development, 42(1), 15-27. Retrieved from https://psycnet.apa.org/record/2001-16133-002

DiPerna, J. C., \& Elliott, S. (1999). Development and validation of the academic competence evaluation scales. Journal of Psycho educational Assessment, 17(3), 207-225. Retrieved from https://asu.pure.elsevier.com

Eich, D. (2008). A Grounded Theory of High-Quality Leadership Programs: Perspectives From Student Leadership Development Programs in Higher Education. Journal of Leadership \& Organizational Studies, 15(2), 176-187. doi:10.1177\%2F1548051808324099

Elliott, S. N., Malecki, C., \& Demaray, M. (2001). New Directions in Social Skills Assessment and Intervention for Elementary and Middle School Students. Exceptionality, 9(1), 19-32. doi:10.1207/S15327035EX091\&2_3

Erozkan, A. (2013). The Effect of Communication Skills and Interpersonal Problem Solving Skills on Social Self- $\quad$ Efficacy. Educational Sciences: Theory and Practice, 13(2), 739-745. Retrieved from https://eric.ed.gov/?id=EJ1017303

Ghulam, B. M., \& Anwar, M. (2011). Comparative Analyses of the Teaching Methods and Evaluation Practices in English Subject at Secondary School Certificate (SSC) and General Certificate of Education (GCE O-Level) in Pakistan. International Education Studies, 4(1), 202-211. Retrieved from https://eric.ed.gov/?id=EJ1066384

Gresham, F. M., Evans, S., \& Elliott, S. N. (1988). Academic and Social Self-Efficacy Scale: Development and initial validation. Journal of Psycho educational Assessment, 6(2), 125-138. doi:10.1177/073428298800600204

Heckhausen, J., \& Wrosch, C. (2015). Challenges to developmental regulation across the life course: What are they and which individual differences matter? International Journal of Behavioral development, 40(2), 145-150. doi:10.1177\%2F0165025415588796

Hess, D., \& Warren, D. (2008). The Meaning and Meaningfulness of Corporate Social Initiatives. Business and Society Review, 113(2), 163-197. doi:10.1111/j.1467-8594.2008.00317.x

House, D. J. (1998). Student attitudes and academic background as predictors of achievement in college English. International Journal of Instructional Media, 25(1), 29. Retrieved from https://search.proquest.com/openview/34d222878be2d0628af564db14475bcd/1

Lazar, S., Jihyun, L., Wenshu, L., \& David J., H. (2012). Confidence: A better predictor of academic achievement than self-efficacy, self-concept and anxiety? Learning and Individual Differences, 22(6), 747-758. doi:10.1016/j.lindif.2012.05.013

Legault, L., Green-Demers, I., \& Pelletier, L. (2006). Why Do High School Students Lack Motivation in the Classroom? Toward an Understanding of Academic Amotivation and the Role of Social Support. Journal of Educational Psychology, 98(3), 567-582. doi:10.1037/0022-0663.98.3.567

Mahamod, Z., \& Somasundram, B. (2017). Effectiveness of Cooperative Learning on Achievement and Motivation of the Student in Learning Malay Language. Creative Education, 8(15). Retrieved from https://www.scirp.org/

Mahmood, N., \& Shinohara, F. (2002). Recognizing the Influence of Assessment Pattern in the Formation of Teaching Style. Journal of Science education in Japan. doi:10.14935/jssej.26.187

Martin, A. J., Nejad, H. G., Colmar, S., \& Liem, G. (2013). Adaptability: How students' responses to uncertainty and novelty predict their academic and non-academic outcomes. Journal of Educational Psychology, 105(3), 728-746. doi:10.1037/a0032794

Memon, G. R. (2007). Education in Pakistan: The key issues, problems and the new challenges. Journal of Management and Social Sciences, 3(1), 47-55.

Michielle, S. F., Robert, J. V., \& Frederic, G. (1995). Academic Motivation and School Performance: Towards a Structured Model. Contemporary Educational Psychology, 20, 257-274. Retrieved from https://lrcs.uqam.ca/wp-content/uploads/2017/04/Academic-motivation-and-schoolperformance.pdf

Riggio, E. R., \& Reichard, J. R. (2008). The emotional and social intelligences of effective leadership: An emotional and social skill approach. Journal of Managerial Psychology, 23(2), 169-185. doi:10.1108/02683940810850808

Rubin, K. H., Coplan, R. J., Fox, N. A., \& Calkins, S. D. (1995). Emotionality, emotion regulation, and preschoolers' social adaptation. Emotions in Developmental Psychopathology, 7(1), 49-62. doi:10.1017/S0954579400006337 
Ryan, R. M., \& Deci, E. L. (2000). Self-determination theory and the facilitation of intrinsic motivation, social development, and well-being. American Psychologist, 55(1), 68-78. Retrieved from http://psycnet.apa.org/buy/2000-13324-007

Scholaro, p. (2018). Education system in Pakistan. Retrieved from https://www.scholaro.com/pro/Countries/Pakistan/Education-System

Schweitzer, R., \& Mc Kenzie, K. (2010). Who Succeeds at University? Factors predicting academic performance in first year Australian university students. Higher Education Research \& Development, 20(1), 21-33. doi:10.1080/07924360120043621

Shaikh, M. A. (2018). Equivalence of 'O' \& 'A' level with SSC \& HSSC in Pakistan. Sindh Board of Technical Education, Karachi. Retrieved from https://www.sbte.edu.pk/wpcontent/uploads/2018/06/Cambridge-Report-13-14Feb2018.pdf

Shujja, S., Malik, F., \& Khan, N. (2015). Social Competence Scale for Adolescents (SCSA): Development and validation within cultural perspective. Journal of Behavioural Sciences, 25(1), 59-77. Retrieved from psycnet.apa.org/record/2015-29715-004

Steinmayr, R., MeiBner, A., Weidinger, A. F., \& Wirthwein, L. (2014). Academic Achievement. Education. doi:10.1093/obo/9780199756810-0108

Tavani, C. M., \& Losh, S. C. (2003). Motivation, self-confidence, and expectations as predictors of the academic performances among our high school students. Child Study Journal, 33(3), 141-151. Retrieved from https://psycnet.apa.org/record/2004-95117-001

Topping, K., Bremner, W., \& Holmes, E. (2000). Social competence: The social construction of the concept. In I. R. Bar-On, \& J. D. Parker (Eds.), The handbook of emotional intelligence: Theory, development, assessment, and application at home, school, and in the workplace (pp. 28-39). San Francisco, CA, US: Jossey-Bass.

Torres, J. B. (2001). Role of self-efficacy, stress, social integration, and family support in Latino college student persistence and health. Journal of Vocational Behavior, 59(1), 53-63.

Utvær, B. S., \& Haugan, G. (2016). The Academic Motivation Scale: Dimensionality, Reliability, and Construct Validity among Vocational Students. Nordic Journal of Vocational Education and Training, 6(2), 17-45. doi:10.3384/njvet.2242-458X.166217

Vallerrand, R. J., Pelletier, L. G., Blais, M. R., Briere, N. M., Senecal, C., \& Vallieres, E. (1992). The Academic Motivation Scale: A Measure of Intrinsic, Extrinsic, and A motivation in Education. Educational and Psychological Measurement. 1003-1017. doi:10.1177\%2F0013164492052004025

Wentzel, K. R. (1991). Social Competence at School: Relation between Social Responsibility and Academic Achievement. Review of Educational Research, 61(1), 1-24. doi: $10.3102 \% 2 F 00346543061001001$

Wigfield, K. R. (1998, June). Academic and Social Motivational Influences on Students' Academic Performance. Spinger Link, 10(2), 155-175. doi:10.1023/A:1022137619834

Zimmerman, B. J., Bandura, A., \& Martinez-Pons, M. (1992). Self-Motivation for Academic Attainment: The Role of Self-Efficacy Beliefs and Personal Goal Setting. American Educational Research Journal, 29(3), 663-676. doi:10.3102\%2F00028312029003663

Zins, J., Weissbert, R., Wang, M., \& Walberg, H. (2004). Building academic success on social and emotional learning: what does the research say? New York, NY: Teachers College Press.

Zsolnai, A. (2002). Relationship Between Children's Social Competence, Learning Motivation and School Achievement. Educational Psychology, 22(3), 317-329. doi:10.1080/01443410220138548 